\title{
Experimental Study of Moisture Ingress in First and Second Levels of Electronic Housings
}

Conseil-Gudla, Helene; Hamm, Gerald; Mueller, Lutz; Hain, Mathias; Ambat, Rajan

Published in:

I E E E Transactions on Components, Packaging and Manufacturing Technology

Link to article, DOI:

10.1109/TCPMT.2018.2799233

Publication date:

2018

Document Version

Peer reviewed version

Link back to DTU Orbit

Citation (APA):

Conseil-Gudla, H., Hamm, G., Mueller, L., Hain, M., \& Ambat, R. (2018). Experimental Study of Moisture Ingress in First and Second Levels of Electronic Housings. I E E E Transactions on Components, Packaging and Manufacturing Technology, 8(11), 1928-1937. https://doi.org/10.1109/TCPMT.2018.2799233

\section{General rights}

Copyright and moral rights for the publications made accessible in the public portal are retained by the authors and/or other copyright owners and it is a condition of accessing publications that users recognise and abide by the legal requirements associated with these rights.

- Users may download and print one copy of any publication from the public portal for the purpose of private study or research.

- You may not further distribute the material or use it for any profit-making activity or commercial gain

- You may freely distribute the URL identifying the publication in the public portal 


\title{
Experimental study of moisture ingress in first and second levels of electronic housings
}

\author{
H. Conseil-Gudla ${ }^{1}$, G. Hamm², L. Müller ${ }^{2}$, M. Hain², R. Ambat ${ }^{1}$ \\ ${ }^{1}$ Materials and Surface Engineering, Department of Mechanical Engineering, Technical University \\ of Denmark, Produktionstorvej, DK-2800 Lyngby, Denmark (helco@mek.dtu.dk) \\ ${ }^{2}$ Robert Bosch GmbH, Automotive Electronics, Tübinger Str. 123, DE-72762 Reutlingen, Germany
}

\begin{abstract}
Moisture uptake of polymer materials used for electronic packaging, and moisture ingress into automotive electronic sensor housings have been studied by exposure to constant and cyclic humidity and temperature conditions. The first level housing is made of epoxy molding compound (EMC) and encapsulates the sensor silicon-chip. The second level housing is made of polybutylene terephthalate (PBT) and contains the EMC attached to a printed circuit board (PCB). The novel approach was to perform in-situ measurements of the temperature and the relative humidity (RH) inside the EMC next to the silicon-chip, and to measure the humidity transfer from outdoor to the second, and through the first level housings up to the chip. The effect of the presence of $\mathrm{PCB}$, and the self-heating of components have been investigated. The results showed that the time constants for humidity to reach $63 \%$ of outdoor conditions are about 2 days and 7 days at $60{ }^{\circ} \mathrm{C}$, for the second and first level housings respectively. Exposure to cyclic conditions showed that the internal RH tends to reach a steady state, close to the mean value of the cyclic outdoor profile, while presence of polymeric materials (as PCB) can act as a humidity buffer, and absorb and desorb water when subjected to temperature fluctuations.
\end{abstract}

Index Terms — Epoxy molding compound, housings, humidity, moisture diffusion, printed circuit board, temperature.

\section{INTRODUCTION}

$\mathrm{I}^{\mathrm{r}}$

$\mathrm{N}$ ORDER TO design and manufacture robust electronic packages, it is important to understand the response of the electronic housings to different and sometimes extreme climate conditions to which they will be subjected in service. Electrical and electronic devices are generally protected from the external environment by the use of enclosures (the second level housing), while the semiconductor devices and components are encapsulated in a resinous thermoset material (the first level housing), often referred to as epoxy molding compound (EMC).

Diffusion of moisture from the atmosphere into these devices and components is one of the major concerns in electronics reliability. Several issues related to the device performance degradation and failures are often found to involve diffusion of moisture during manufacturing, storage, or operation as the root cause of failure [1-2]. Automotive electronic housings in particular are exposed to environments in which the temperature and moisture contents can vary drastically depending on the geographical location and the location of the housings inside the automobile. The three important factors to be considered for better reliability of such devices with respect to external climate conditions are: (i) the temperature, (ii) the relative humidity $(\mathrm{RH})$, which is the actual pressure of water vapour expressed as a percentage of the saturated vapour pressure, and (iii) the dew-point temperature (DP), which is the temperature to which vapour at a given pressure must be cooled to reach saturation, and then condensed as liquid water. The temperature and humidity levels within the housings are important factors for the electronic reliability, and are indicators of the environmental loads at the installation location and the consequential failure mechanisms during the usage in the field.

Polymer based materials are widely used for housings of electronic devices and as parts of the electronic assembly. Polymeric materials generally absorb moisture from the atmosphere and undergo degradation by plasticization, swelling and micromechanical damages [3-7], hydrolytic cleavage of polymeric chains etc., thus reducing the overall mechanical properties and integrity of the housings, such as decreasing their elastic modulus, shear strength or fracture toughness etc..[7]. In addition, the polymeric housings also act as a medium for the diffusion of moisture to the interior of the housing, which greatly affects the reliability of the electronic circuits [8-9]. Several reports have illustrated the effect of humidity on reliability of electronic devices, and studied the different types of moisture induced corrosion failure modes such as electrochemical migration (ECM) and short circuit [10-17], conductive anodic filament (CAF) formation between embedded copper conduction lines in glass epoxy laminates [18-20] etc. The internal moisture inside the 
polymeric second level housing further aggravates these failures due to diffusion into the first level housing. This increases the local moisture concentration inside the EMC and induces other intermittent and permanent electronic failures due to interfacial delamination, reduction of the interfacial adhesion strength, material expansion, and mechanical failure [21].

Optimal designing of the electronic packaging for reliable electronic device performance thus requires a full understanding of the underlying mechanism of moisture diffusion into the second level polymer packaging materials used in electronics, and how it leads to humidity build-up inside the housing. Studies on water absorption in polybutylene terephthalate (PBT) material [22-23], in printed circuit board (PCB) laminate [4;24-26], and in EMC material [3;6;28-31] have been investigated, but to a limited extent, and very little is known about moisture penetration and build up inside the electronic housing under the actual climate conditions with different levels of electronic packaging.

In view of this, the current study focuses on the moisture profiles in industrial automotive electronic sensor housings. Moisture diffusion and storage capacities of plastic packages have been investigated quantitatively by employing sorption tests using plane sheet materials. The ingress of moisture into the housings has been studied and measured with $\mathrm{RH}$ and temperature sensors by exposing the automotive electronic sensor devices to various external climate conditions. The moisture ingress into the EMC package has been studied by molding of the EMC material directly on a lead frame with $\mathrm{RH}$ and $\mathrm{T}$ sensors for in situ measurements of moisture diffusion. Therefore, the ingress of moisture through the different levels of housings protection has been measured.

\section{MATERIALS AND METHODS}

\section{A. Materials used for investigations}

The materials selected for the sorption tests are plane sheets of PBT with and without hydrolysis resistance (HR) property (casing material for the second level housings), plane sheets of EMC (material of the first level housing), and PCBs (which are placed in the second level housings). The tests have been performed in order to determine the diffusion and solubility coefficients of each material involved in the humidity build-up into the housings. PBT material is a thermoplastic, semi-crystalline polyester reinforced with $30 \%$ glass fibers (30GF). EMC is a composite material made up of an epoxy matrix (Biphenyl material) with silica fillers $(\sim 88 \mathrm{wt} \%)$, which also contains stress relief agents, flame retardants, and other additives. The PCBs are made of halogen and halogen-free FR4 laminates, which are glass fibers reinforced epoxy resin with copper foils bonded on to the sides for etching out the circuits. Table 1 summarizes the different sample materials used for the investigations along with the notations used for them in this paper.

The humidity build-up inside the automotive electronic sensor housings industrial housings has been studied in two different second level housings, namely Housing I and Housing II, for which the casing wall materials are in PBT 30GF with and without HR respectively. Tests with and without PCB placed inside the housings have been performed (respectively PCB I and PCB II). RH and T sensors were placed inside the housings and connected to existing electrical pins avoiding any extra hole for external electrical connection. The setup of second level housing, cables and connector, typically has a helium leak-rate of $<10^{-6} \mathrm{mbar} \cdot \mathrm{L} \cdot \mathrm{s}^{-1}$, i.e. it is air-tight. For the in-situ measurement of humidity build-up in the first level housing, the RH and T sensors have been connected to a lead frame PLCC44 (Cu) (due to the size requirement of the sensors) using an Ag-filled epoxy with a curing process at $120{ }^{\circ} \mathrm{C}$ for $2 \mathrm{~h}$. The lead frame has then been molded with the EMC material at $175^{\circ} \mathrm{C}$ and 87 bar pressure followed by a post-mold-cure at $150{ }^{\circ} \mathrm{C}$ for $5 \mathrm{~h}$. Then the leads were stamped and trimmed followed by a Sn plating of the leads (Figure 1). Figure 2 summarizes the different configurations used for the humidity build-up tests in the housings. 
TABLE I

DETAILS OF MATERIALS USED FOR THE WATER SORPTION STUDY

\begin{tabular}{|c|c|c|}
\hline Abbreviation & Material & Thickness (mm) \\
\hline PBT HR & $\begin{array}{l}\text { Poly-butyleneterephthalate - } \\
30 \% \text { glass fibers - hydrolysis } \\
\text { resistant }\end{array}$ & 4 \\
\hline PBT no HR & $\begin{array}{l}\text { Poly-butyleneterephthalate - } \\
30 \% \text { glass fibers - no hydrolysis } \\
\text { resistant }\end{array}$ & 4 \\
\hline EMC & $\begin{array}{l}\text { Biphenyl material - } \\
\sim 88 \text { wt.\% silica fillers }\end{array}$ & 1.3 \\
\hline PCB I & $\begin{array}{c}\text { (Printed circuit board from } \\
\text { Housing I) } \\
\text { halogen FR4 laminates }\end{array}$ & 1.5 \\
\hline РCB II & $\begin{array}{l}\text { (Printed circuit board from } \\
\text { Housing II) } \\
\text { halogen-free FR4 laminates }\end{array}$ & 1.25 \\
\hline
\end{tabular}

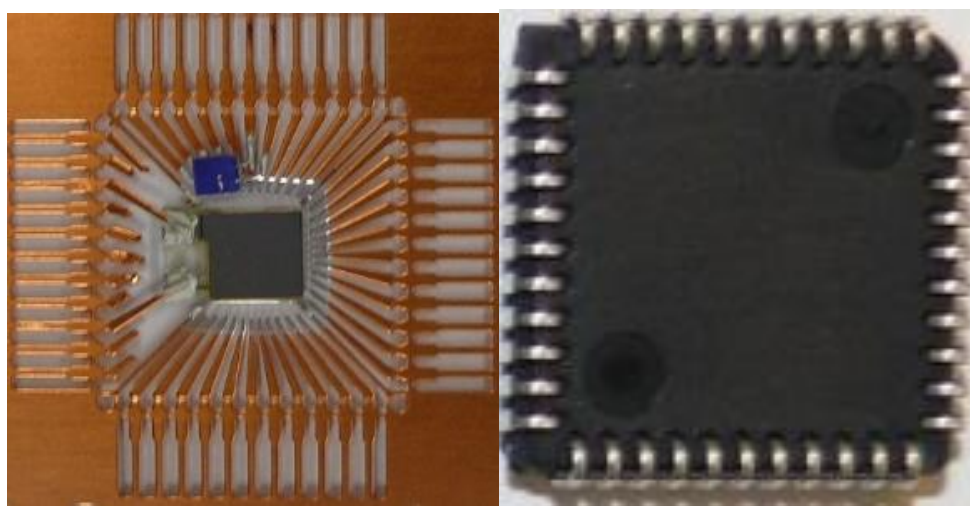

Fig. 1. Pictures of a) Cu lead frame PLCC44 with connected T and RH sensors and b) EMC material after molding process. 


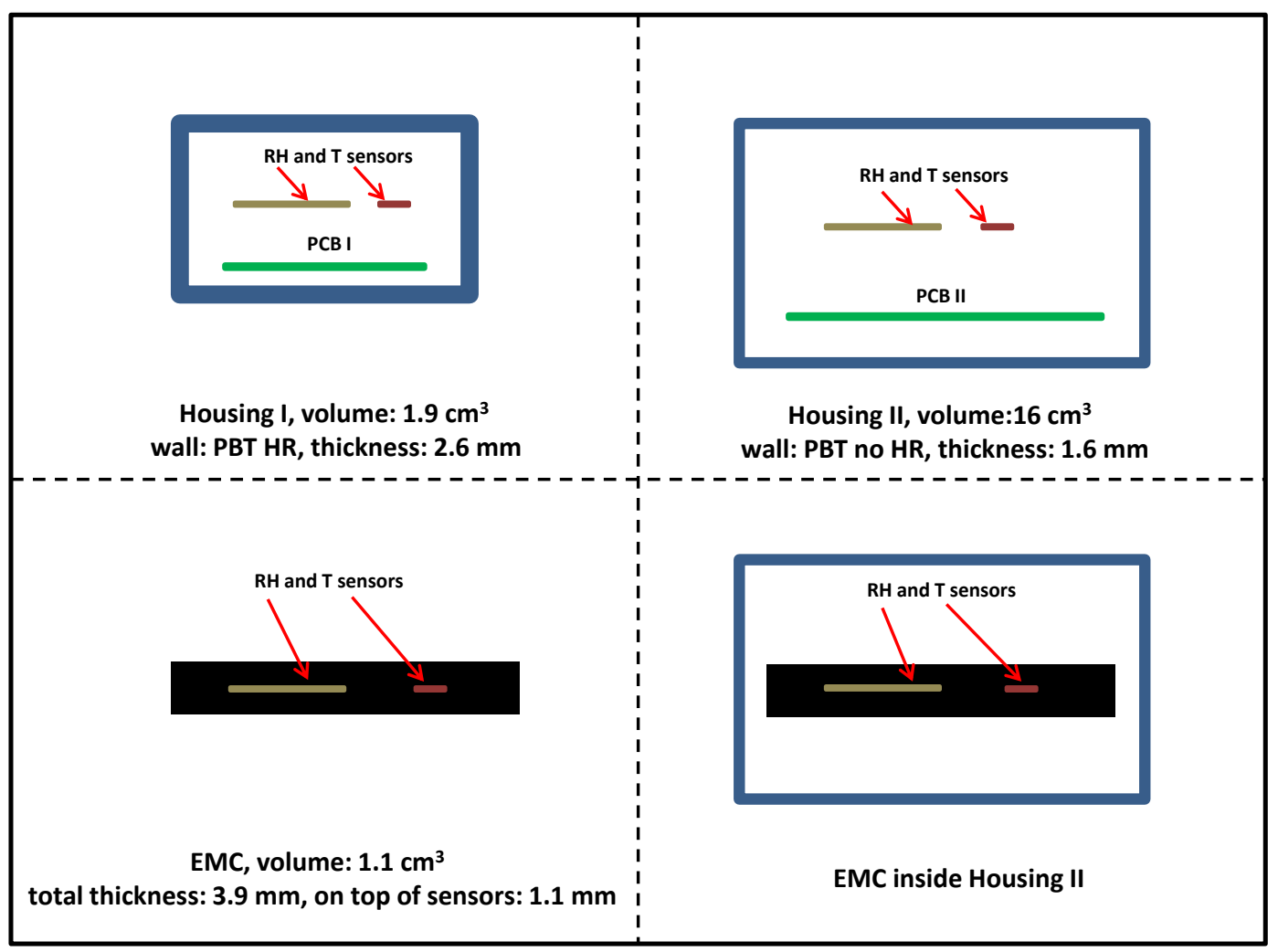

Fig. 2. Schematic of the four configurations used for the humidity build up tests in the industrial housings.

\section{B. Sorption test of the polymer materials}

The moisture uptake by the polymers was investigated to determine the diffusion and the solubility coefficients as well as the moisture saturation level of the packaging materials. The two PBT materials with and without HR, EMC material, and PCBs used for the investigation were tested at conditions of $25{ }^{\circ} \mathrm{C}$ and full immersion in water, $40{ }^{\circ} \mathrm{C}$ and $93 \% \mathrm{RH}, 60{ }^{\circ} \mathrm{C}$ and $93 \% \mathrm{RH}$, and $85{ }^{\circ} \mathrm{C}$ and $85 \% \mathrm{RH}$. These are the test conditions of the automotive components, required by the specifications of vehicle manufacturers (IEC standard 60028-2-56).

The materials were dried prior to the test to remove any residual humidity. A standard baking condition for electronic packaging namely $24 \mathrm{~h}$ at $125{ }^{\circ} \mathrm{C}$ was employed. The initial weight was measured using a calibrated precision electronic balance $(0.1 \mathrm{mg})$ followed by the exposure of the samples in a climatic chamber (CTS Hechingen, GER, type C 40/200). The samples were removed periodically from the climatic chamber to measure the increase in weight (within $5 \mathrm{~min}$ ) and placed again in the chamber for further sorption. Assuming an initial dry sample at the start of the tests, the weight gain of the samples during the sorption experiment corresponds to the weight of moisture uptake into the materials (average value of three samples).

The percentage of weight gain $X\left({ }_{\text {wt. }} \%\right)$ was calculated using the following formula:

$$
X(t)=\frac{\Delta m(t)}{m_{0}} \times 100
$$

where $m_{0}(\mathrm{~kg})$ is the initial weight of the sample and $\Delta m(t)$ is the change of weight of the sample (kg) after exposure for a time period $t$. Considering the Fickian absorption for one-dimensional case of an infinite plate of thickness $l$ and the integration over the thickness of the bulk film, the fractional mass uptake of the specimen as a function of time is [32]:

$$
\frac{\Delta m(t)}{\Delta m_{\infty}}=1-\frac{8}{\pi^{2}} \sum_{n=0}^{\infty} \frac{1}{(2 n+1)^{2}} \exp \left(\frac{-D(2 n+1)^{2} \pi^{2}}{4 l^{2}} t\right)
$$


where $\Delta m_{\infty}$ is the change of weight at equilibrium $(\mathrm{kg}), l$ is the thickness of the material $(\mathrm{m})$, and $D$ is the diffusion coefficient $\left(\mathrm{m}^{2} \cdot \mathrm{s}^{-1}\right)$. The diffusion coefficient of bulk materials $D$ can be found from the slope of the initial linear part of the moisture uptake curve together with the sample weight at saturation state. The initial stage of moisture absorption $\left(m(t) / m_{\infty}<0.5\right)$ can be simplified as follows:

$$
\frac{\Delta m(t)}{\Delta m_{\infty}}=4\left(\frac{D t}{\pi l^{2}}\right)^{1 / 2}
$$

The solubility coefficient can be calculated from the following equation:

$$
S=\frac{\rho}{p_{A}} \cdot \frac{\Delta m_{f}}{m_{0}}
$$

where $S$ is the solubility coefficient $\left(\mathrm{kg} \cdot \mathrm{m}^{-3} \cdot \mathrm{Pa}^{-1}\right), \rho$ is the volumetric mass density $\left(\mathrm{kg} \cdot \mathrm{m}^{-3}\right)$ of the material, $p A$ is the partial water vapor pressure in ambient air $(\mathrm{Pa})$, while_ $m f$ is the final change of weight of the sample $(\mathrm{kg})$.

\section{Humidity exposure of housing and measurement of internal humidity build up}

The housings were baked-out at $125{ }^{\circ} \mathrm{C}$ for 24 hours prior to the test, and were exposed to temperature and humidity conditions in a climatic chamber (CTS Hechingen, GER, type C 40/200). The T sensor (PT1000) and RH sensor (HC1000 - capacitive sensor) placed inside the housings as described before were used to record the interior temperature and humidity with a sweep time of 2 min (Datalogger GMH 3350, Greisinger electronic, Regenstauf, GER).

The constant climatic conditions used for the investigations were: $40{ }^{\circ} \mathrm{C} / 93 \% \mathrm{RH}$ and $60{ }^{\circ} \mathrm{C} / 93 \% \mathrm{RH}$ (IEC standard 60028-2-56). The build-up of the internal relative humidity $R H(t)$ was monitored and the time constant $\tau$ has been determined using the relation:

$$
R H(t)=R H_{0}\left(1-e^{\frac{-t}{\tau}}\right)
$$

where $R H_{0}$ is the set RH in the climatic chamber, $t$ is the time [s], and $\tau$ is the time constant for the internal RH to reach the fraction $\left(1-\mathrm{e}^{-1}\right)=0.63$ of the ambient value $[\mathrm{s}]$.

Additionally, two cyclic conditions were studied. The first condition represents $24 \mathrm{~h}$ climate measured in Jakarta, Indonesia ( $1^{\text {st }}$ of July 2012) repeated for 115 days (Figure 3), while the second condition corresponds to T and RH data recorded inside an engine compartment of a car driving in southern China in the summer season, including the simulation of driving and parking periods. The conditions were $30{ }^{\circ} \mathrm{C} / 85 \% \mathrm{RH}$ for $22 \mathrm{~h}$ and $80{ }^{\circ} \mathrm{C} / 10 \% \mathrm{RH}$ for $2 \mathrm{~h}$ respectively. 


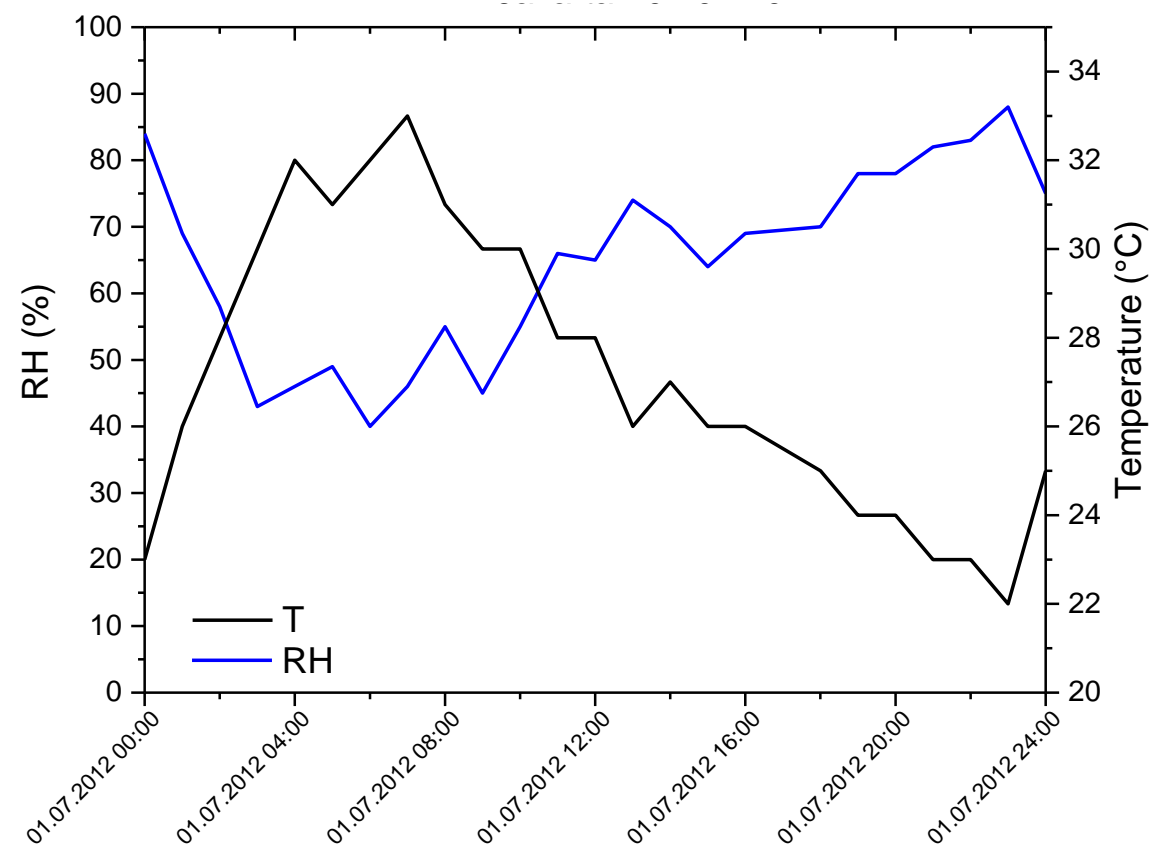

Fig. 3. Tropical climatic profile in Jakarta, Indonesia ( $1^{\text {st }}$ of July 2012).

\section{RESULTS AND DISCUSSION}

\section{A. Sorption test of the polymer packaging materials}

\section{a. Moisture uptake of PBT GF30 and EMC materials}

While the reliability of equipment is mostly related to the RH [12;33], the process of moisture diffusion through materials is related to the AH, i.e. the moisture concentration in air [34], and is dependent on the temperature. As the studied housings are truly air-tight, determining the moisture characteristic of the housing materials is important as permeation through the housing walls is the dominant transport mechanism for moisture equilibrium between the inside and the outside of the housing to reach similar AH levels.

Sorption tests have been performed with the different packaging materials. Figure 4 shows the plots of the experimental weight gain data showing moisture uptakes as a function of the square root of time for PBT and EMC materials. The sorption test shows that the rate of water absorption and the saturated water content (i.e. water content in equilibrium with its environment) of the different materials are dependent on the temperature. The water uptakes of the PBT samples in Figures $4 \mathrm{a}$ and $\mathrm{b}$ show an initial slope related to the relative rate of moisture absorption followed by a plateau region corresponding to the saturation level. The EMC material on the other hand showed two-stage water absorption (Figure 4c) with the first part saturating after about $120 \mathrm{~h}$ followed by a new increase of moisture absorption slope. The moisture uptake stabilized after about $700 \mathrm{~h}$ of exposure. This type of water absorption has been defined as a dual stage diffusion model [30;35-38]. During the first stage, the water molecules from the environment migrate to the microscopic pores or voids in the material to achieve a pseudo-concentration equilibrium. With increasing time (second stage), the water molecules become chemically bonded to the polymer chains of hydroxyl groups, leading to a significant swelling of the material.

Since the PBT material contains ester group, it is prone to hydrolysis and embrittlement in hot and moist environments [22]. Although some stabilizers are added to increase the hydrolysis resistance of PBT, the HR property of the PBT did not have a significant effect on the diffusion at the tested temperatures.

Figure 5 shows the value of the temperature dependent parameters such as diffusion and solubility coefficients calculated from the absorption data. The diffusion and solubility coefficients of the EMC material were lower than for 
the PBT materials, and are in accordance with published results [6-7;31]. This could be attributed to the higher amount of fillers in the mold compound (about 88 wt. \%) than in the PBT material (about 30 wt. \%), which do not absorb moisture [23]. Therefore the presence of fillers could extend the path of diffusion through the thickness of the material with higher fillers content [39], while Shirangi et al. [1] showed that a higher amount of maximum moisture content could be expected at the interface between the lead frame and the bulk molding compound in the actual package. These results show that diffusion through the second level housing will be faster (higher diffusion coefficient), but also that the amount of water stored in the casing wall of the second level housing will be higher.
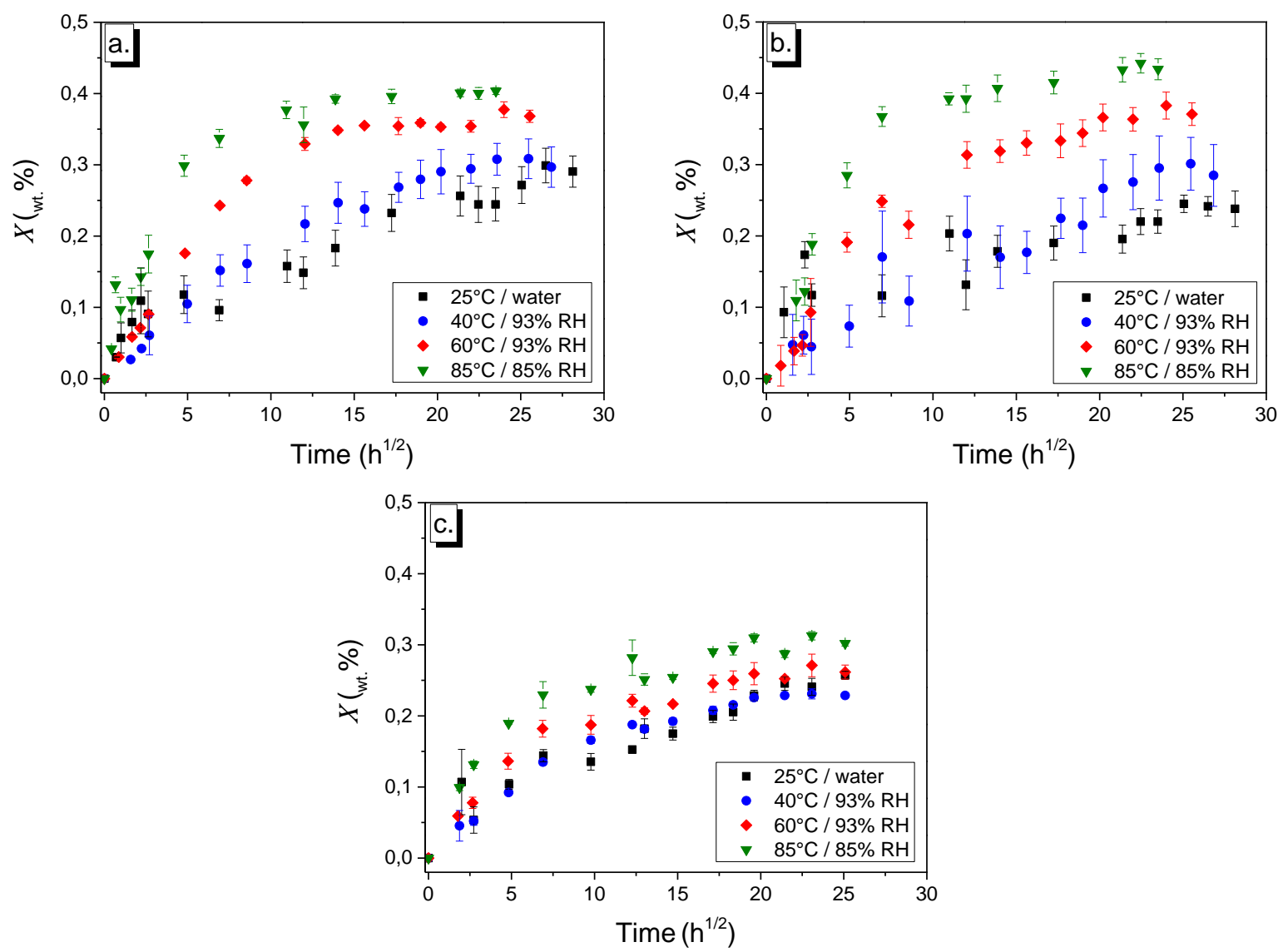

Fig. 4. Moisture uptake curves for PBT: a) with HR and b) without HR, and c) EMC materials. 


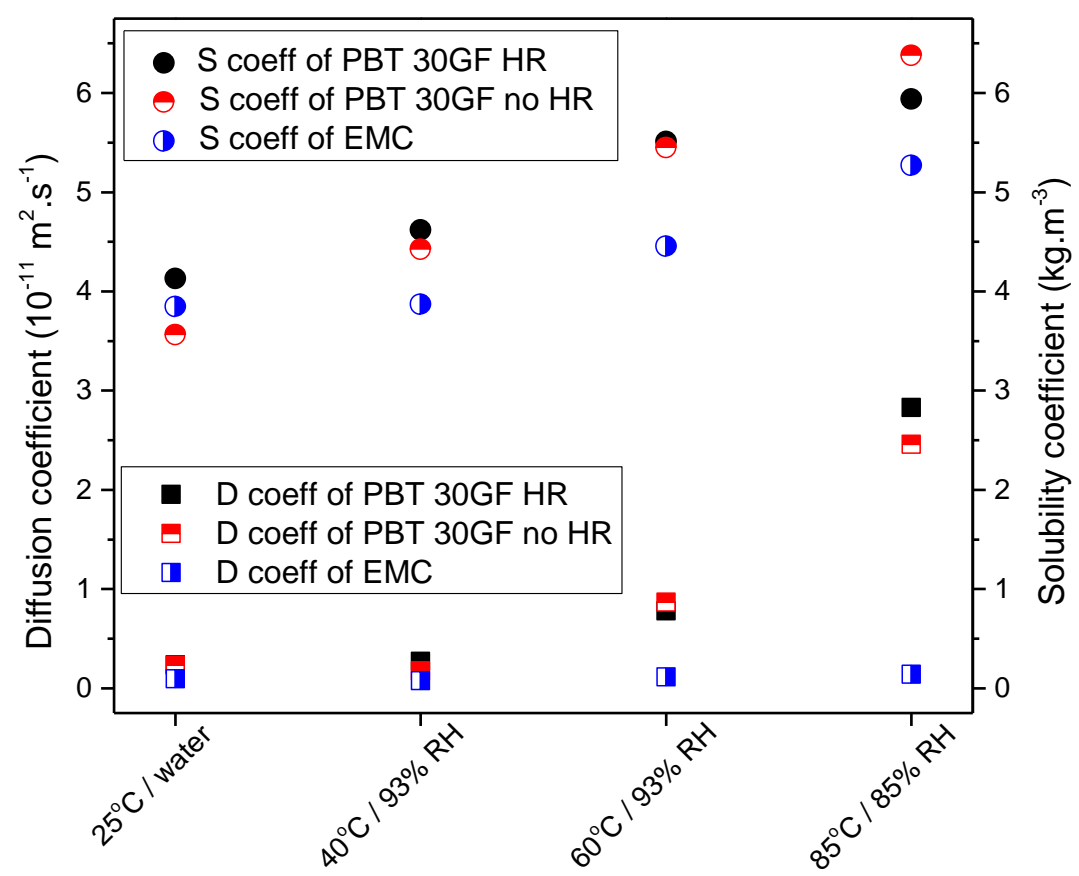

Fig. 5. Diffusion and solubility coefficients calculated from the absorption profile.

\section{b. Moisture uptake of PCBs}

The moisture absorption profiles of the PCB I and PCB II at 40 and $60{ }^{\circ} \mathrm{C}$ and at $93 \%$ RH can be observed in Figure 6. Regardless of the temperature, the moisture absorptions of the PCBs show an initial linear increase followed by a slow increase without reaching a plateau after 45 days of testing under humid conditions. The weight of the PCBs continued to increase up to 0.35 and 0.44 wt. $\%$ for the PCB I and up to 0.28 and 0.35 wt. $\%$ for the PCB II respectively at $40{ }^{\circ} \mathrm{C}$ and $60{ }^{\circ} \mathrm{C}$. This corresponds to the water absorption of the laminates and of the components in the PCBs. Conseil-Gudla et al. [27] showed that the first linear part corresponds to the water adsorption/absorption of the solder mask coated on the PCB laminate, and the second linear part corresponds to the water absorption into the bulk PCB laminate. In absolute value, PCB I and PCB II can hold up to 4 and $16 \mathrm{mg}$ of water respectively from the surrounding humid air coming through the second level housings. The water absorption as well as the water storage capacities of these materials will influence the moisture ingress and profile inside the housings. 


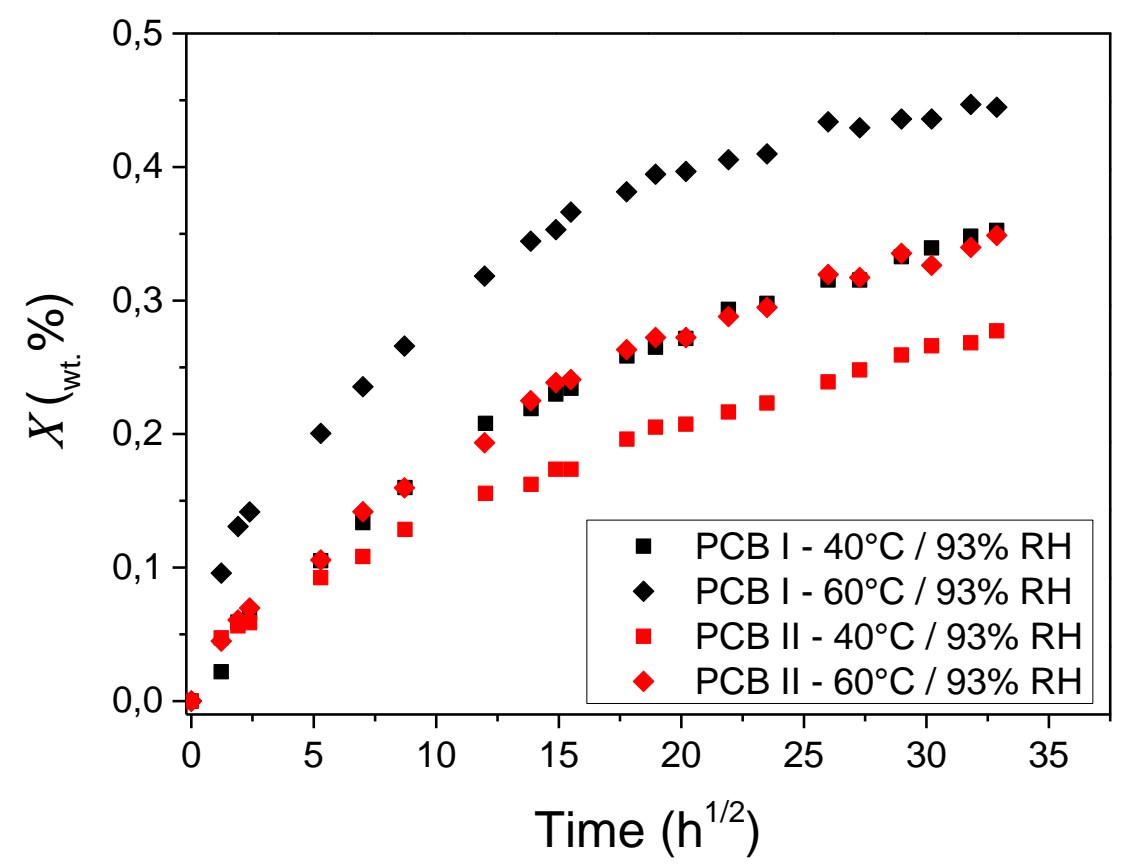

Fig. 6. Moisture absorption by the PCB associated with the Housing I and II.

\section{B. Exposure of the housings to constant conditions}

\section{a. Effect of temperature, volume of housing, and presence of PCB}

The automotive housings have been exposed to constant conditions $\left(40{ }^{\circ} \mathrm{C}\right.$ and $60{ }^{\circ} \mathrm{C}$ at $\left.93 \% \mathrm{RH}\right)$ for investigations. Figure 7 shows the moisture ingress into the Housing I and Housing II (with and without PCB), into the EMC package, and into the EMC package placed inside the Housing II. Some residual moisture prior to the exposure can be observed in Housing II and in the EMC placed inside Housing II, showing that the baking process did not fully dry-out the packages. Nevertheless, the calculated time constants $\tau$ (time to reach $63 \%$ of the outdoor condition) takes in account the initial RH level, and published work of semi-empirical prediction of humidity build-up [40] showed that the initial RH level is not an influential factor on the moisture transfer time constant.

The lower volume of the Housing I led to a faster humidity build-up than in the Housing II. The time constants $\tau$ were respectively 6.8 and 1.6 days for the Housing I, and 10 and 2.7 days for the Housing II, at $40{ }^{\circ} \mathrm{C}$ and $60{ }^{\circ} \mathrm{C}($ Table 2). The humidity ingress in the Housing I was slower in the presence of the PCB I, with a reduction of $4 \%$ and $8 \%$ RH at the end of the test. The presence of the PCB II has slightly reduced the final RH inside the Housing II, however no significant difference was observed. The volume ratio of PCB / Housing is about $14 \%$ and $6 \%$ respectively for the Housings I and II, which could explain the higher effect of water absorption of the PCB I on the overall reduction of internal humidity in the Housing I, while its low rate of water absorption implies a slow rate of internal humidity reduction in comparison to without PCB I in Housing I. Moreover, some residual moisture in PCB II could have been released inside Housing II when exposed to high temperature (i.e. $60{ }^{\circ} \mathrm{C}$ ) and has to be considered.

The in situ measurement of humidity build-up inside the EMC mounted on the lead frame was investigated under 60 ${ }^{\circ} \mathrm{C}$. Figure 7 shows the humidity profile measured using the embedded $\mathrm{RH}$ sensor (taken in consideration that the thickness of the EMC material on top of the sensor is about $1.1 \mathrm{~mm}$ ). It can be observed that the low diffusion coefficient of the EMC has induced a slower moisture ingress in the first level housing (EMC) compared to the second level housing (PBT). Moreover, three regions of the curve indicate: i) the diffusion through the thickness of the material until reaching the humidity sensing top part of the RH sensor, ii) the moisture diffusion through the bulk material, and iii) a saturated plateau. The time interval for the first region was about $17 \mathrm{~h}$, while the time constant $\tau$ was reached after around 7 days of exposure (Table 2). In order to determine the transfer function of the humidity through the second and first level housings, in situ measurements of the RH profile in the EMC package placed inside the Housing II has been 
performed. Figure 7 shows the RH profile where a delay of the time constant $\tau$ about 11 days can be observed in comparison to the humidity build-up in the Housing II (Table 2). The humidity had to diffuse through the second level housing wall and then through the EMC material to be detected by the molded sensors.

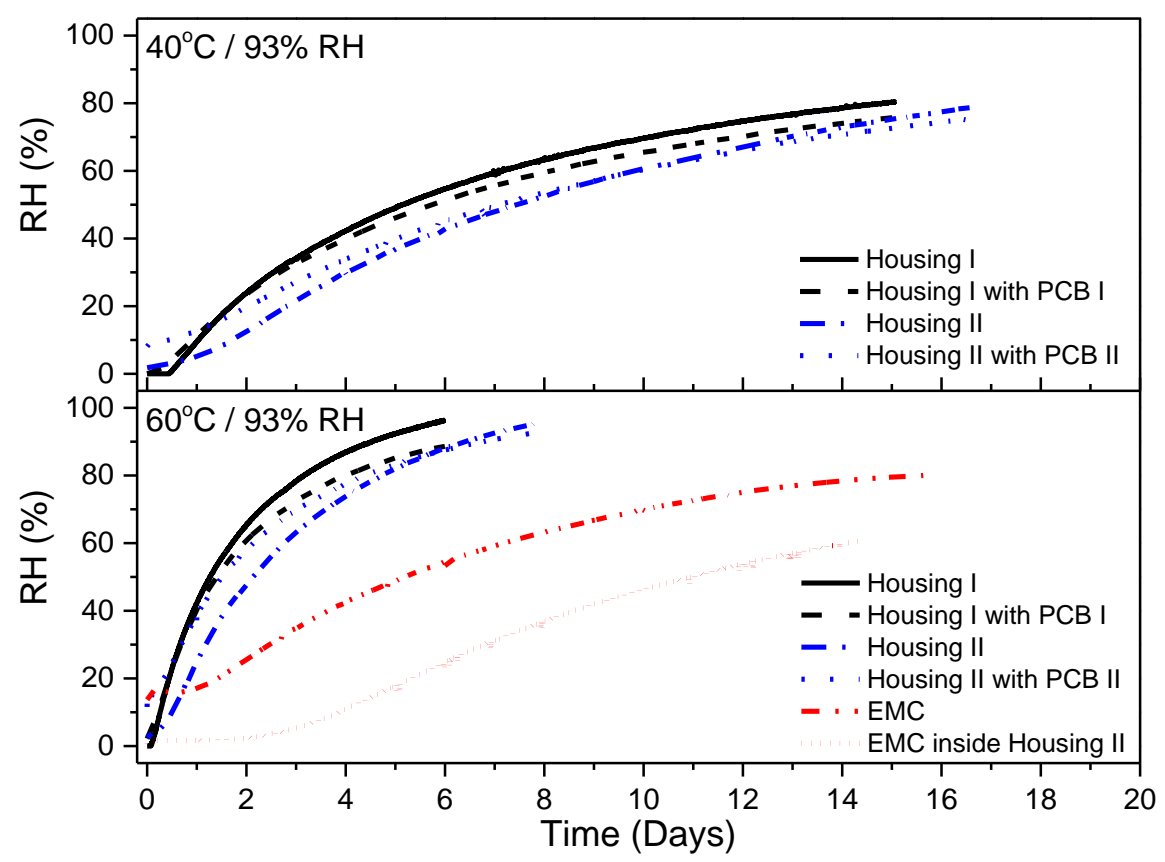

Fig. 7. Moisture ingress into the Housing I, Housing II and EMC, with and without additional components inside.

\section{b. Effect of self-heating}

In order to simulate the effect of self-heating inside the enclosure on humidity build-up, a heater (in this case a LED) has been placed inside the Housing II. Preliminary analysis of thermal profile of PCB has shown possible self-heating of components (mainly from ASIC: application-specific integrated circuit) up to an over-temperature of $25{ }^{\circ} \mathrm{C}$ in such devices. Figure 8 shows the moisture profiles in the Housing II with an internal temperature of 5 and $10{ }^{\circ} \mathrm{C}$ higher than the outside condition. The effect has been to lower the internal $\mathrm{RH}$ level up to $79 \%$ and $69 \% \mathrm{RH}$ after 8 days of exposure, while 93\% RH was reached in the Housing II without internal heat. The moisture ingress into the housing tends to equilibrate the internal $\mathrm{AH}$ with the outdoor $\mathrm{AH}$, while higher internal temperature leads to lower internal RH. 


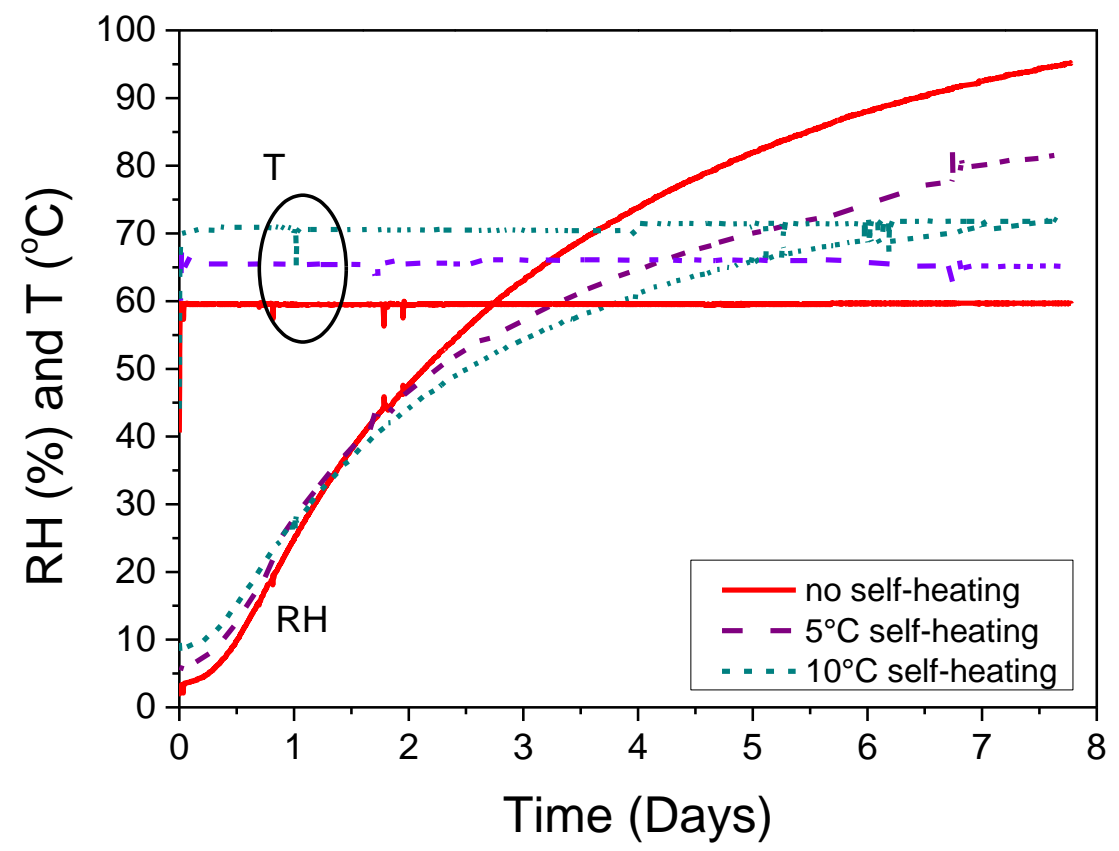

Fig. 8. Moisture ingress into the Housing II exposed to $60{ }^{\circ} \mathrm{C} / 93 \% \mathrm{RH}$, with and without self-heating from component.

The time constant of the housings (Table 2) is in the order of days or weeks depending on the temperature level when exposed to constant conditions. The time is long compared to the timescale for temperature and humidity changes of the weather during a typical day. Actual outdoor temperature and humidity are not constant; therefore the housing protection and time constant for moisture penetration can play a major role.

TABLE II

TIME CONSTANTS OF THE HUMIDITY INGRESS IN THE HOUSINGS

\begin{tabular}{ccc}
\hline \hline & $40{ }^{\circ} \mathrm{C} / 93 \% \mathrm{RH}$ & $60^{\circ} \mathrm{C} / 93 \% \mathrm{RH}$ \\
\hline Type of Housing & \multicolumn{3}{c}{ Time constant $\tau$ (days) } \\
\hline Housing I & 6.8 & 1.6 \\
Housing I with PCB I & 7.7 & 1.9 \\
Housing II & 10.0 & 2.7 \\
Housing II with PCB II & 10.0 & 2.2 \\
Housing II with self-heating of & $/$ & 3.3 \\
$5^{\circ} \mathrm{C}$ & & 3.9 \\
Housing II with self-heating of & $/$ & 8.1 \\
$10^{\circ} \mathrm{C}$ & $/$ & 13.7 \\
EMC & $/$ & \\
EMC in Housing II & & \\
\hline \hline
\end{tabular}




\section{Exposure of housings to cyclic conditions}

\section{a. Simulated climate conditions of the day/night profile in Jakarta, Indonesia}

The profile simulating the weather in Jakarta, Indonesia (Figure 9) shows that the internal RH level in the housings increased smoothly and did not follow the cyclic profile of the outdoor condition. Instead the internal humidity profile tends to reach a steady state value. After 115 days of exposure, the RH reached the maximum values corresponding to the steady-state of 78 and $89 \%$ RH for the Housing I and II. The in situ measurements of RH profiles in the EMC package and in the EMC package placed in the Housing II showed an increase of the internal RH starting after 9.5 and 14.2 days respectively. A smooth increase of the internal RH was then observed, and reached a steady-state around $47 \%$ RH inside the EMC, but did not reach a plateau even after 4 months of exposure for the EMC placed inside the Housing II. Similar to the constant exposure conditions, final RH in the EMC is lower than the surrounding air.

An important function of moisture protection by the housing materials is the attenuation of the ever changing ambient conditions, and in this tropical exposure simulation, the attenuation factor of the second level housing was about 10 to $20 \% \mathrm{RH}$, and this factor was enhanced up to 55\% (after 4 months of exposure) in the EMC placed inside the second level housing.

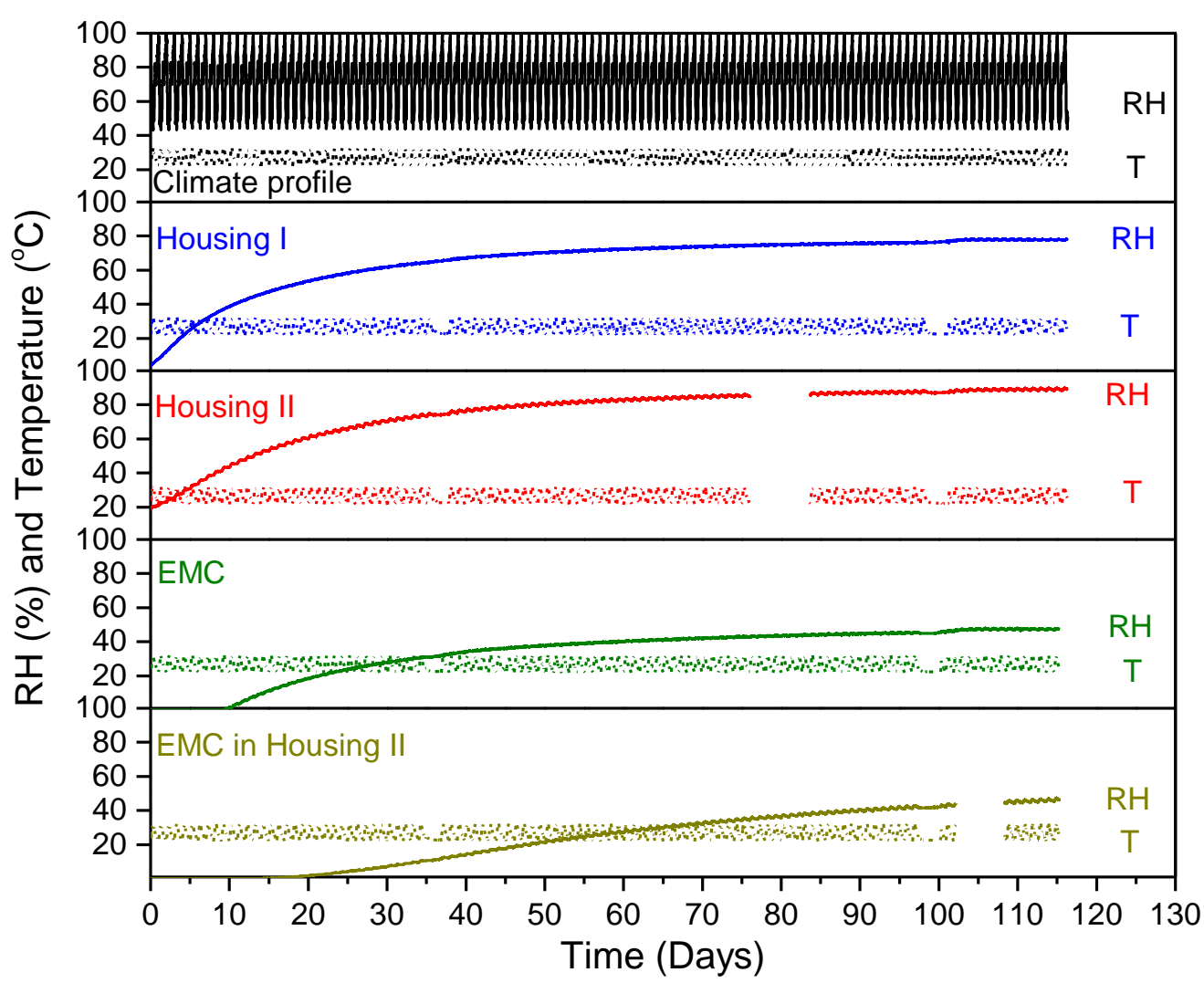

Fig.9. Climate profiles in Housing I, Housing II, EMC and EMC in Housing II exposed to the day/night profile in Jakarta, Indonesia.

b. Simulated climate inside the engine compartment 
Figure 10 shows the internal RH profiles of the Housings I and II with and without PCB exposed to the simulated climate inside the engine compartment of a car driven in South China. In both cases without PCB, a similar profile can be observed. During the first step at $30{ }^{\circ} \mathrm{C} / 85 \% \mathrm{RH}$, the internal $\mathrm{RH}$ increased slowly. When the temperature is suddenly changed to $80{ }^{\circ} \mathrm{C}$, a drop in the internal RH can be observed. However, when the outdoor RH level was $10 \%$, the internal RH continued to increase despite its level was above the outdoor level of humidity. This excess of humidity can only come from the release of moisture from the inner wall. When the new step at $30{ }^{\circ} \mathrm{C} / 85 \% \mathrm{RH}$ started, the internal RH increased suddenly at a higher level than at the previous step at $30{ }^{\circ} \mathrm{C} / 85 \% \mathrm{RH}$. This shows that more humidity has been accumulated in the internal volume during the step at high temperature $\left(80{ }^{\circ} \mathrm{C}\right)$. Then the $\mathrm{RH}$ level decreased slowly until the next step, suggesting a re-absorption of moisture into the internal walls of the housings. This aspect is confirmed by the plots of the AH profiles (Figure 11), where an increase of the air water concentration is observed at each cycle at $80{ }^{\circ} \mathrm{C}$, and reached higher levels than the outdoor conditions (up to $125 \mathrm{~g} \cdot \mathrm{m}^{-3}$, while outdoor AH is about $29 \mathrm{~g} \cdot \mathrm{m}^{-3}$ ). This shows that the packaging materials that have absorbed moisture from a humid environment can release this moisture when exposed to a dry air (release only to external climate) or at higher temperature (release to internal and external climate) [2;9]. This is clear from the results in Figures 10 and 11, where the moisture diffused and absorbed by the walls during the step at $30{ }^{\circ} \mathrm{C}$ and $85 \% \mathrm{RH}$ has been released during the step at $80{ }^{\circ} \mathrm{C}$ and $10 \% \mathrm{RH}$. The drying period of the cycle (corresponding to the driving time of $2 \mathrm{~h}$ per day) has allowed the humidity absorbed by the wall material of the housing to be released outside and inside of the housing volume, while this step was not long enough to dry out completely the housing.

Figure 12 shows the profile of the internal RH in the Housing I when the last step at $80{ }^{\circ} \mathrm{C} / 10 \% \mathrm{RH}$ (after 12 days of exposure to the cyclic conditions) has been maintained for $48 \mathrm{~h}$. It can be seen that $4 \mathrm{~h}$ was almost necessary to observe the first decrease of the internal humidity, while $48 \mathrm{~h}$ of exposure to $80{ }^{\circ} \mathrm{C}$ did not allow to reach fully the equilibrium with the outdoor ( $\mathrm{RH}$ is still above $10 \% \mathrm{RH}$ ). This shows that the heat induced during short periods of driving time is not enough to dry out the housings inside the car, which on the other hand could create higher level of humidity inside the housings due to release of moisture from the wall material.

However, the presence of PCB has a similar effect in both cases on the internal RH, the absorption and release of moisture from the PCB have contributed to act as a buffer, and have reduced the variation of the internal RH during the simulated driving period. Nevertheless, the humidity profile in the Housing II with PCB II is quite different, where a higher AH level (Figure 11) can be observed compared to the profile without PCB during the step at $80{ }^{\circ} \mathrm{C}$. It seemed that the PCB II did not absorb moisture, but released a large quantity of water during this step. A main difference between PCB I and PCB II is that PCB II contained a capacitor component with high thermal capacity. Therefore, a new experiment has been carried out (Figure 13) with the Housing II using the same PCB II, but without the capacitor component. The new profile is then similar to the one obtained in the Housing I with the PCB I. That shows that the delay in the temperature change of the heavy thermal mass capacitor during the step at $80{ }^{\circ} \mathrm{C}$ may have been a specific place for the condensation to occur, and the presence of liquid water may have increased the overall level of internal $\mathrm{RH}$ in the Housing II. The accumulation of moisture inside the PCB can be detrimental for the electronic reliability, which will lead to abrupt unpredictable loss of insulation resistance when a voltage is applied, with the formation of short circuit due to the growth of a subsurface filament known as CAF [10;41] or other types of failure modes.

The in situ measurements in the EMC package (Figures 10 and 11) did not show any increase of humidity until day 4 of the exposure, which can be attributed to the low diffusion coefficient of the EMC material. Then, a slow smooth increase of RH is observed, with an increase of $\mathrm{RH}$ and of the internal water concentration $\left(C_{\text {int }}\right)$ at each step at $80{ }^{\circ} \mathrm{C}$ suggesting that the EMC material released also moisture during the step at high temperature. In that case, there is no air gap between the material and the sensor, and any release of moisture from the EMC material will directly be in contact with the RH sensor surface. The in situ RH measurement in the EMC inside the Housing II did not show any increase of humidity until day 12 of the exposure. However, an increase of $\mathrm{RH}$ and $C_{\text {int }}$ were also observed during the step at $80{ }^{\circ} \mathrm{C}$ due to the release of residual moisture present at the beginning of the test in the EMC material. 


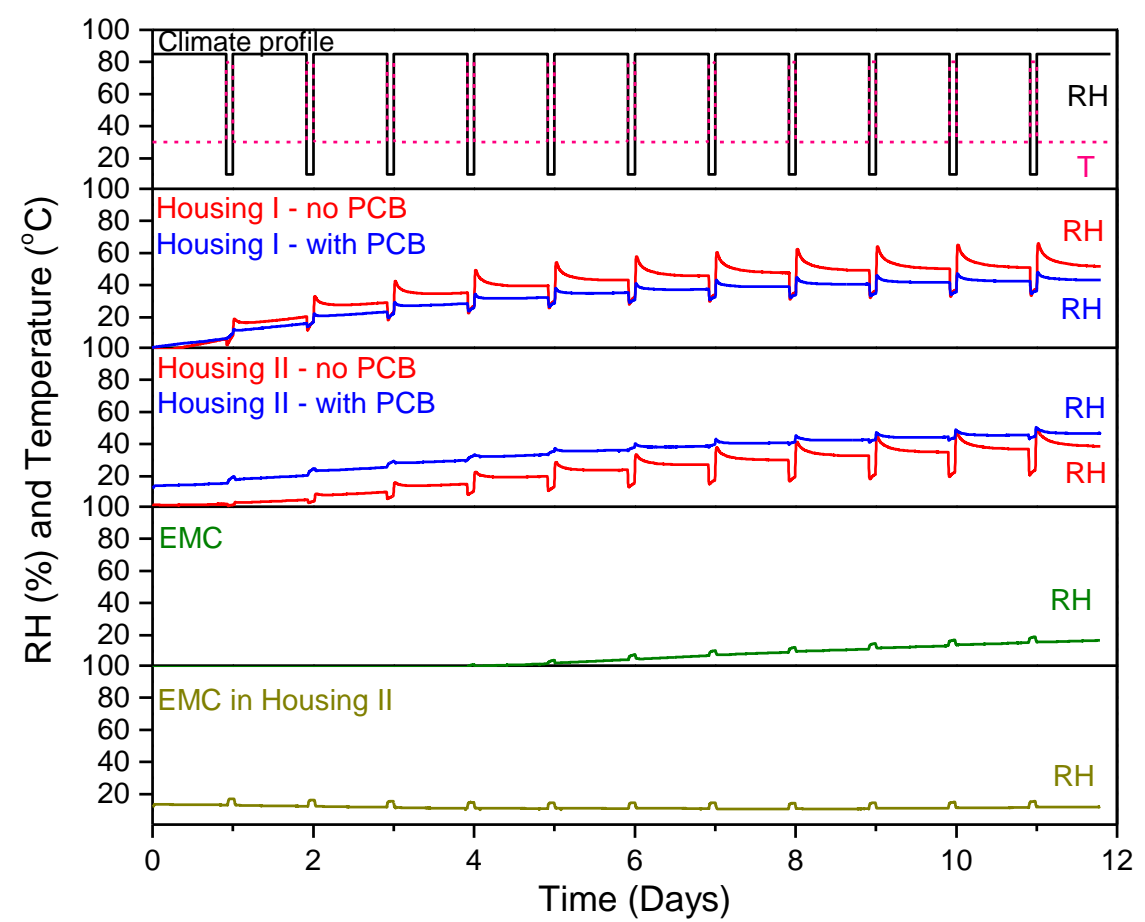

Fig. 10. Climate profiles in Housing I, Housing II, EMC and EMC in Housing II exposed to the cyclic conditions: $30{ }^{\circ} \mathrm{C} / 85 \% \mathrm{RH} / 22 \mathrm{~h}$ and $80{ }^{\circ} \mathrm{C} /$ $10 \% \mathrm{RH} / 2 \mathrm{~h}$.

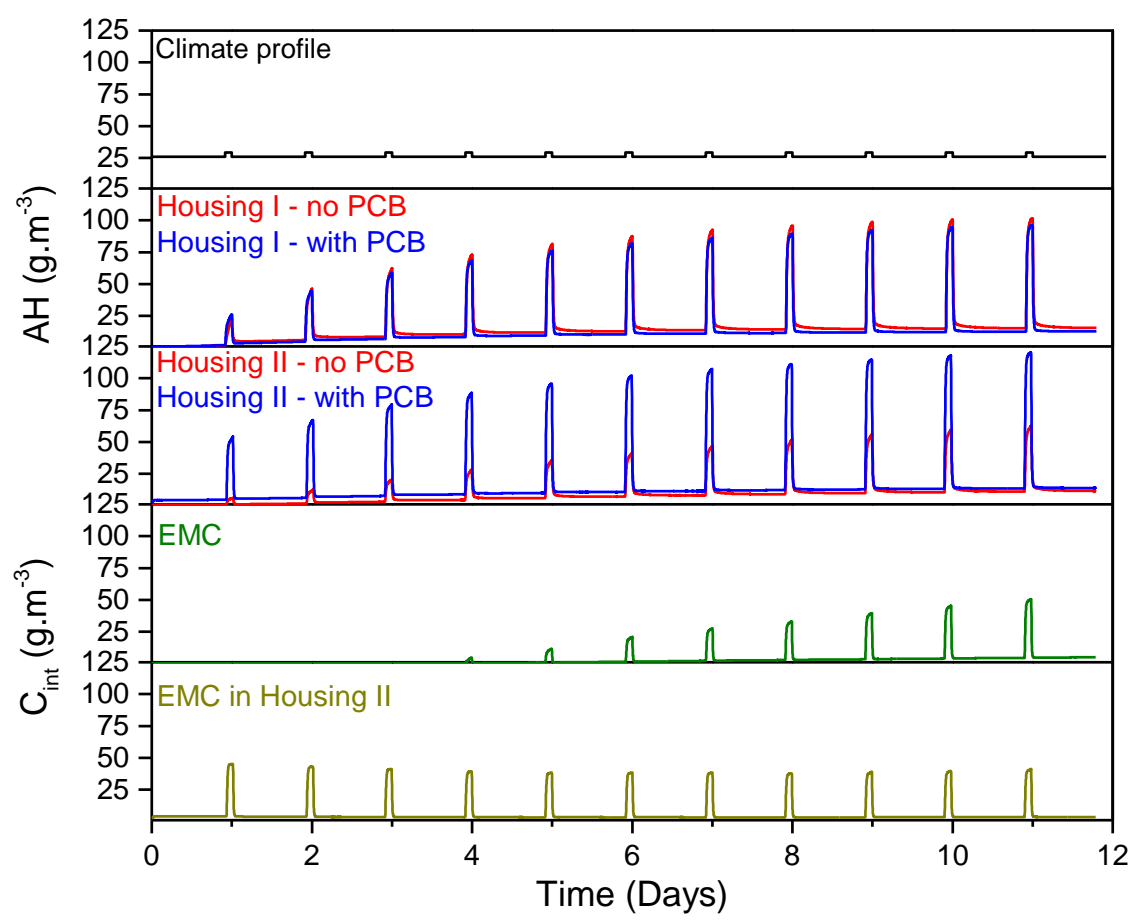

Fig. 11. AH profiles in Housing I, Housing II, and $C_{\text {int }}$ in EMC and EMC in Housing II exposed to the cyclic conditions: $30{ }^{\circ} \mathrm{C} / 85 \% \mathrm{RH} / 22 \mathrm{~h}$ and $80{ }^{\circ} \mathrm{C} / 10 \% \mathrm{RH} / 2 \mathrm{~h}$. 


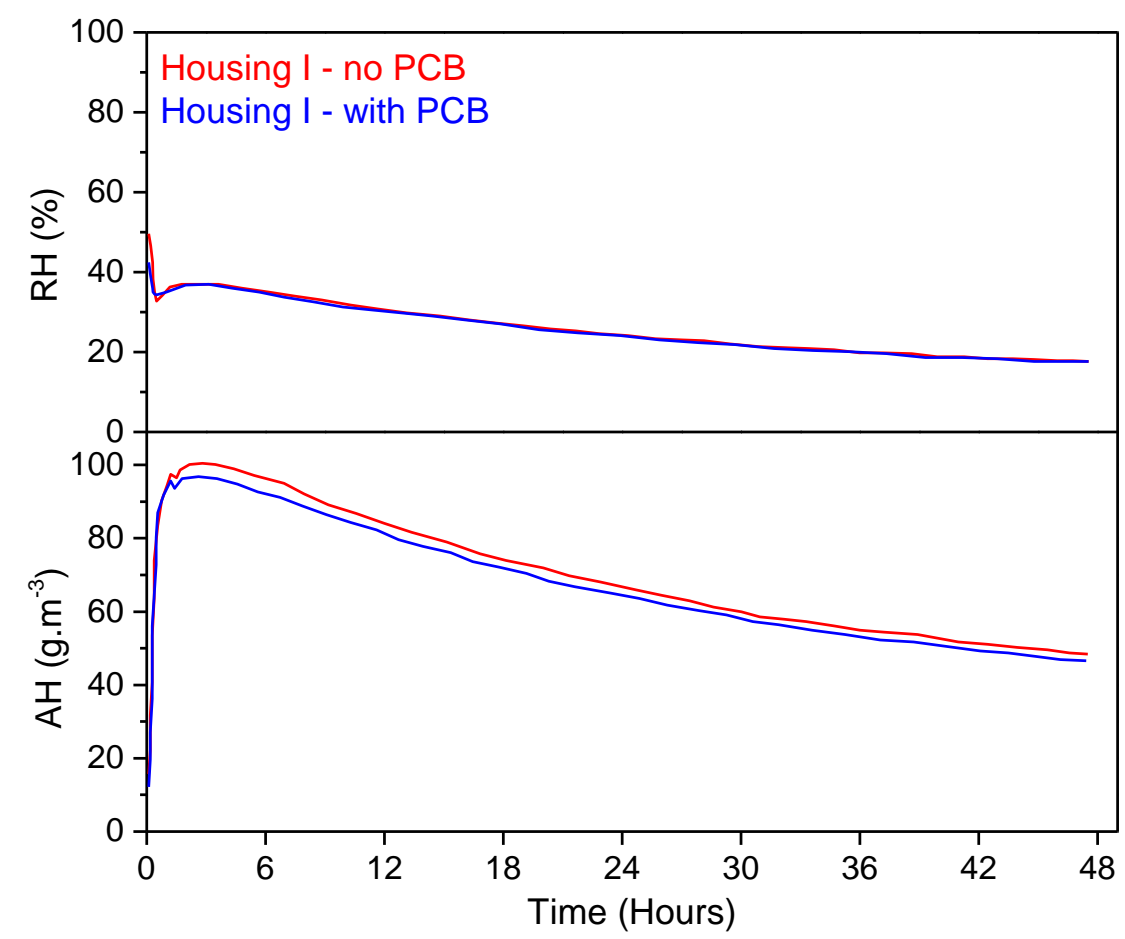

Fig. 12. Climate profile in Housing I, exposed to the last cycle: $80^{\circ} \mathrm{C} / 10 \% \mathrm{RH}$ during $48 \mathrm{~h}$.

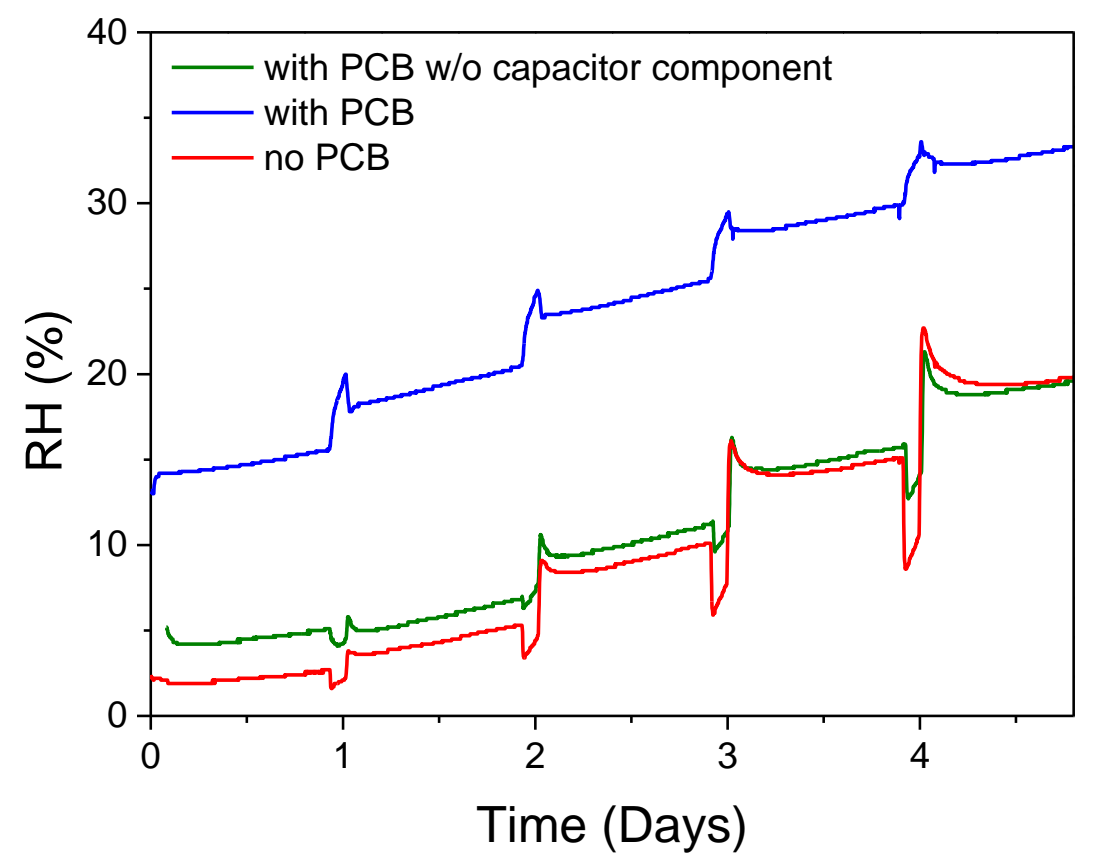

Fig. 13. Effect of the presence of component on PCB on the climate profile in Housing II, exposed to the cyclic conditions: $30{ }^{\circ} \mathrm{C} / 85 \%$ RH $/ 22 \mathrm{~h}$ and $80^{\circ} \mathrm{C} / 10 \% \mathrm{RH} / 2 \mathrm{~h}$.

\section{CONCLUSION}

The investigations reported in this paper clearly show the influence of temperature, presence of PCB, and self-heating 
on internal humidity build-up, and the transfer of humidity from outdoor to second and first level of protection, with PBT and EMC material. Further experimental simulations of the cyclic climatic conditions such as day and night cycles in tropical area, and climate in an engine compartment of a car, have shown how the external fluctuation in humidity and temperature influences the internal humidity conditions inside the housings.

1. While the moisture diffusion coefficient of PBT materials did not seem to be greatly influenced by the hydrolysis resistance property, it is around 6 times higher than the diffusion coefficient of EMC at $60{ }^{\circ} \mathrm{C}$. The in-situ measurement of moisture ingress inside EMC allowed to observe the transfer function of humidity from outdoor into the second level housing and into the first level housing. The low diffusion coefficient of the EMC material has induced a high attenuation factor of moisture ingress, up to 55\% $\mathrm{RH}$ after 4 months of exposure to a tropical profile, when the first level housing was placed inside the second level housing.

2. The presence of plastic parts inside the housing, like PCB laminates which absorb water, acted as a humidity buffer and reduced the internal variation of humidity changes. Components with high thermal mass can show delay in temperature changes, and condensation can occur if their surface temperature is below the dew point.

3. While self-heating during on time can reduce the moisture ingress in the housing, the heat induced during short periods of driving time may not be enough to dry out the housings inside the car, and could actually create higher level of humidity inside the housings, due to release of moisture from the wall material.

\section{ACKNOWLEDGEMENTS}

This work was supported by Robert Bosch $\mathrm{GmbH}$ and by the ICCI project funded by the Danish Council for Independent Research, Technology and Production (FTP) and IN-SPE project funded by the Innovation Fund Denmark.

\section{REFERENCES}

[1] M. H. Shirangi and B. Michel, "Mechanism of moisture diffusion, hygroscopic swelling, and adhesion degradation in epoxy molding compounds," in Proc. 41st Annu. Int. Symp. Microelectron. (IMAPS), 2008, pp. 1082-1089.

[2] J. B. Jacobsen, J. P. Krog, A. Riis, A. H. Holm, and L. Rimestad, "Climate-protective packaging: Using basic physics to solve climatic challenges for electronics in demanding applications," IEEE Ind. Electron. Mag., vol. 8, no. 3, pp. 51-59, Sep. 2014.

[3] M. G. Lu, M. J. Shim, and S. W. Kim, "Effects of moisture on properties of epoxy molding compounds," J. Appl. Polym. Sci., vol. 81, no. 9, pp. 2253-2259, 2001.

[4] M. Ma, L. Sood, and B. Pecht, "Effect of moisture on thermal properties of halogen-free and halogenated printed-circuit-board laminates," IEEE Trans. Device Mater. Rel., vol. 11, no. 1, pp. 66-75, Mar. 2011.

[5] Y. C. Lin and X. Chen, "Investigation of the effect of hygrothermal conditions on epoxy system by fractography and computer simulation," Mater. Lett., vol. 59, nos. 29-30, pp. 3831-3836, 2005.

[6] Y. C. Lin, "Investigation of the moisture-desorption characteristics of epoxy resin," J. Polym. Res., vol. 13, no. 5, pp. 369-374, 2006.

[7] Y. C. Lin and X. Chen, "Moisture sorption-desorption-resorption char- acteristics and its effect on the mechanical behavior of the epoxy system," Polymer, vol. 46, no. 25, pp. 11994-12003, 2005.

[8] H. Conseil, V. C. Gudla, M. S. Jellesen, and R. Ambat, "Humidity build- up in a typical electronic enclosure exposed to cycling conditions and effect on corrosion reliability," IEEE Trans. Compon., Packag., Manuf. Technol., vol. 6, no. 9, pp. 1379-1388, Sep. 2016.

[9] H. Conseil-Gudla, Z. Staliulionis, M. S. Jellesen, M. Jabbari, J. H. Hattel, and R. Ambat, "Humidity buildup in electronic enclosures exposed to constant conditions," IEEE Trans. Compon., Packag., Manuf. Technol., vol. 7, no. 3, pp. 412-423, Mar. 2017.

[10] A. Fan, X. Zhou, and J. Chandra, "Package structural integrity analy- sis considering moisture," in Proc. 58th Electron. Compon. Technol. Conf. (ECTC), May 2008, pp. 1054-1066

[11] H. Conseil, M. S. Jellesen, and R. Ambat, "Contamination profile on typical printed circuit board assemblies vs soldering process," Soldering Surf. Mount Technol., vol. 26, no. 4, pp. 194-202, 2014.

[12] V. Verdingovas, M. S. Jellesen, and R. Ambat, "Impact of $\mathrm{NaCl}$ contamination and climatic conditions on the reliability of printed circuit board assemblies," IEEE Trans. Device Mater. Rel., vol. 14, no. 1, pp. 42-51, Mar. 2014.

[13] V. Verdingovas, M. S. Jellesen, and R. Ambat, "Solder flux residues and humidity-related failures in electronics: Relative effects of weak organic acids used in no-clean flux systems," J. Electron. Mater., vol. 44, no. 4, pp. 1116-1127, 2015.

[14] H. Conseil, V. Verdingovas, M. S. Jellesen, and R. Ambat, "Decompo- sition of no-clean solder flux systems and their effects on the corrosion reliability of electronics," J. Mater. Sci., Mater. Electron., vol. 27, no. 1, pp. 23-32, 2015.

[15] D. Minzari, M. S. Jellesen, P. Møller, and R. Ambat, "On the electro- chemical migration mechanism of tin in electronics," Corrosion Sci., vol. 53, no. 10, pp. 3366-3379, 2011.

[16] V. Verdingovas, M. S. Jellesen, and R. Ambat, "Influence of sodium chloride and weak organic acids (flux residues) on electrochemical migration of tin on surface mount chip components," Corrosion Eng., Sci. Technol., vol. 48, no. 6, pp. 426-435, 2013. 
[17] B. Song, M. H. Azarian, and M. G. Pecht, "Effect of temperature and relative humidity on the impedance degradation of dust-contaminated electronics,” J. Electrochem. Soc., vol. 160, no. 3, pp. C97-C105, 2013.

[18] J. A. Augis, D. G. DeNure, M. J. LuValle, J. P. Mitchell, M. R. Pinnel, and T. L. Welsher, "Humidity threshold for conductive anodic filaments in epoxy glass printed wiring boards," in Proc. 3rd Int. SAMPE Electron. Conf., Electron. Mater. Process., vol. 3. 1989, pp. 1023-1030.

[19] B. Rudra, D. Jennings, and M. Pecht, "Assessing time-to-failure due to conductive filament formation in multi-layer organic laminates," IEEE Trans. Compon., Packag., Manuf. Technol. B, vol. 17, no. 3, pp. 269-276, Aug. 1994.

[20] D. Leslie, A. Dasgupta, and J. W. C. de Vries, "Quantifying mois- ture diffusion into three-dimensional axisymmetric sealants," in Proc. 14th Int. Conf. Thermal, Mech. Multi-Phys. Simulation Experim. Microelectron. Microsyst. (EuroSimE), Apr. 2013, pp. 1-4.

[21] A. A. O. Tay and T. Lin, "Moisture diffusion and heat transfer in plastic ic packages," IEEE Trans. Compon., Packag., Manuf. Technol. A, vol. 19, no. 2, pp. 186-193, Jun. 1996.

[22] Z. A. M. Ishak and Q. N. C. Lim, "Effect of moisture absorption on the tensile properties of short glass fiber reinforced poly(butylene terephthalate)," Polym. Eng. Sci., vol. 34, no. 22, pp. 1645-1655, 1994.

[23] Z. A. M. Ishak, A. Ariffin, and R. Senawi, "Effects of hygrothermal aging and a silane coupling agent on the tensile properties of injection molded short glass fiber reinforced poly(butylene terephthalate) com- posites," Eur. Polym. J., vol. 37, no. 8, pp. 1635-1647, 2001.

[24] M. G. Pecht, H. Ardebili, A. A. Shukla, J. K. Hagge, and D. Jennings, "Moisture ingress into organic laminates,” IEEE Trans. Compon. Packag. Technol., vol. 22, no. 1, pp. 104-110, Mar. 1999.

[25] C. A. Smith, "Water absorption in glass fibre-epoxide resin laminates," Circuit World, vol. 14, no. 3, pp. 22-26, 1988.

[26] H. Zecha, C. Früh, R. Ratchev, E. Biehl, and T. Zerna, "Absorption and diffusion of water in printed circuit boards," in Proc. 36th Int. Spring Seminar Electron. Technol. (ISSE), May 2013, pp. 121-126.

[27] H. Conseil-Gudla, V. C. Gudla, S. Borgaonkar, M. S. Jellesen, and R. Ambat, "Investigation of moisture uptake into printed circuit board laminate and solder mask materials," J. Mater. Sci., Mater. Electron., vol. 28, no. 8, pp. 6138-6151, 2017.

[28] X. Chen, S. Zhao, and L. Zhai, "Moisture absorption and diffusion characterization of molding compound," J. Electron. Packag., vol. 127, no. 4, pp. $460-465,2005$.

[29] T. Y. Lin, B. Njoman, D. Crouthamel, K. H. Chua, S. Y. Teo, and Y. Y. Ma, "The impact of moisture in mold compound preforms on the warpage of PBGA packages," Microelectron. Rel., vol. 44, pp. 603-609, Apr. 2004.

[30] H. Shirangi, J. Auersperg, M. Koyuncu, H. Walter, W. H. Müller, and B. Michel, "Characterization of dual-stage moisture diffusion, residual moisture content and hygroscopic swelling of epoxy mold- ing compounds,” in Proc. 9th Int. Conf. Thermal, Mech. Multi-Phys. Simulation Experim. Microelectron. Micro-Syst. (EuroSimE), Apr. 2008, pp. 1-8.

[31] Y. C. Lin and X. Chen, "Investigation of moisture diffusion in epoxy system: Experiments and molecular dynamics simulations," Chem. Phys. Lett., vol. 412, nos. 4-6, pp. 322-326, 2005.

[32] X. J. Fan, S. W. R. Lee, and Q. Han, "Experimental investiga- tions and model study of moisture behaviors in polymeric materials," Microelectron. Rel., vol. 49, no. 8, pp. 861-871, 2009.

[33] V. Verdingovas, M. S. Jellesen, and R. Ambat, "Relative effect of solder flux chemistry on the humidity related failures in electronics," Soldering Surf. Mount Technol., vol. 27, no. 4, pp. 146-156, 2015.

[34] M. Tencer, "Moisture ingress into nonhermetic enclosures and packages. A quasi-steady state model for diffusion and attenuation of ambi- ent humidity variations," in Proc. 44th Electron. Compon. Technol. Conf. (ECTC), May 1994, pp. 196-209.

[35] J. A. Barrie, P. S. Sagoo, and P. Johncock, “The sorption and diffusion of water in epoxy resins,” J. Membrane Sci., vol. 18, pp. 197-210, Mar. 1984.

[36] M. G. McMaster and D. S. Soane, "Water sorption in epoxy thin films," IEEE Trans. Compon., Hybrids, Manuf. Technol., vol. 12, no. 3, pp. 373-386, Sep. 1989.

[37] G. K. van der Wel and O. C. G. Adan, "Moisture in organic coatings- Areview," Prog. Organic Coat., vol. 37, pp. 1-14, Nov. 1999.

[38] M. D. Placette, X. Fan, J.-H. Zhao, and D. Edwards, "Dual stage mod- eling of moisture absorption and desorption in epoxy mold compounds," Microelectron. Rel., vol. 52, no. 7, pp. 1401-1408, 2012

[39] H. Park, "Characterization of moisture diffusion into polymeric thin film," Exp. Mech., vol. 53, no. 9, pp. 1693-1703, 2013.

[40] T. Braun et al., "Enhancement of barrier properties of encapsulants

for harsh environment applications," in Proc. 62nd Electron. Compon. Technol. Conf. (ECTC), May/Jun. 2012, pp. 1418-1425.

[41] P. S. Nasirabadi, H. Conseil-Gudla, S. Mohanty, M. Jabbari, R. Ambat, and J. H. Hattel, "Semi-empirical prediction of moisture build-up in an electronic enclosure using analysis of variance (ANOVA)," in Proc. IEEE 18th Electron. Packag. Technol. Conf. (EPTC), Nov./Dec. 2016, pp. 785790.

[42] H. Qi, S. Ganesan, and M. Pecht, "No-fault-found and intermittent failures in electronic products,” Microelectron. Rel., vol. 48, no. 5, pp. 663$674,2008$. 


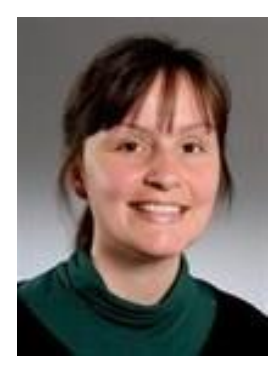

Helene Conseil-Gudla received the M.Sc. degree in Materials Science from the engineering school Polytech'Lille, Lille, France. She is currently a Ph.D. student at the Department of Mechanical Engineering, Technical University of Denmark (DTU), Lyngby, Denmark. Her current research interests include empirical understanding of humidity related effects inside electronic enclosures and related corrosion failure mechanisms.

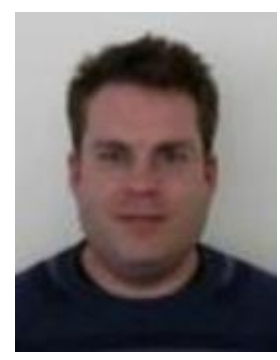

Gerald Hamm received the Dipl. Ing $(\mathrm{FH})$ of automation technology from the Reutlingen University, Germany. He is responsible for the assessment and release of sensor devices applications in vehicles with focus on media and environmental aspects at Robert Bosch GmbH, Reutlingen, Germany. He assesses the environmental impact in order to record the loads and develops different measuring methods and measuring instruments.

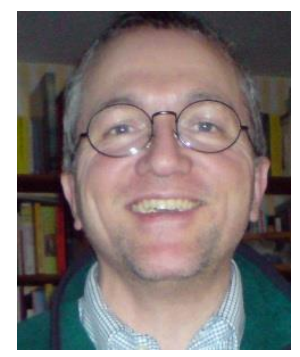

Lutz Müller received the Dr.-Ing. degree in Chemistry from the Technical University of Dortmund, Germany. He was a research engineer with central research and development at Robert Bosch GmbH, Hildesheim, Germany. He then became a research engineer with focus on surface chemistry applications at Robert Bosch CR, Gerlingen, Germany. He is currently senior expert for corrosion and chemistry of materials at Robert Bosch GmbH, Automotive Electronics, Reutlingen, Germany. His current research interests are corrosion of electronics (from second level housing up to corrosion of semiconductor metallization), materials interactions (polymers, metals, adhesives) and thermolysis reactions of hazardous chemicals and lithium batteries (as he is also active member of the fire service).

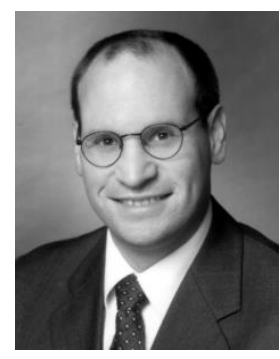

Mathias Hain received his Ph.D. in Physics from Darmstadt Institute of Technology, Germany. He joint University of Connecticut, USA as Research Fellow in 2003. In 2004 he continued his work as project manager for automotive pressure sensors at Robert Bosch GmbH. Since 2015 he is Senior Expert for reliability with focus on Sensors and ECU Braking Systems. His interests cover robust design, climatic loads, lean development and data management.

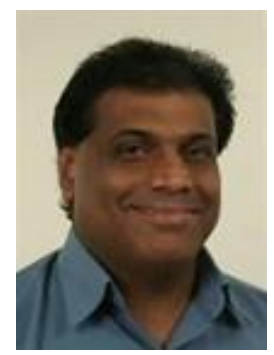

Rajan Ambat received his $\mathrm{PhD}$ from the Indian Institute of Science, Bangalore, India. He is currently a Professor with the Department of Mechanical Engineering, Technical University of Denmark, Lyngby, Denmark, and the Manager of the Centre for Electronic Corrosion and Consortium for Climatically Reliable Electronics, Lyngby, Denmark. He teaches courses on materials in advanced applications and products, including materials in electronics and corrosion reliability issues. His current research interests include corrosion reliability of electronic devices, materials for electronic contacts, high-resolution electrochemical measurements and test methods for electronic corrosion, aluminium alloys and corrosion in oil and gas. 